care. Cardiac puncture during the second trimester has been used to destroy an affected fetus without apparent harm to the normal twin, who was later delivered safely. ${ }^{8}$ Though the risk of miscarriage of the normal twin is presumably increased, cardiac puncture offers a possible, if unpalatable, alternative to the stark choice of either abortion of a normal fetus or acceptance of a handicapped infant.

Twins occur in at least $1 \%$ of term pregnancies, and are more liable to miscarriage and premature birth. When an atrisk pregnancy is suspected to be multiple both genetic counselling and amniocentesis should be left to the experts.

\footnotetext{
${ }^{1}$ Clinical Genetics Society, Bulletin of the Eugenics Society, suppl 3, November 1978.

2 MRC Report on Amniocentesis, British fournal of Obstetrics and Gynaecology, 1978, 85, suppl 2.

3 Hunter, A G W, and Cox, D M, Clinical Genetics, 1979, 16, 34.

${ }^{4}$ Campbell, S, in Prenatal Diagnosis of Hereditary Disorders, 2nd edn. Illinois, C C Thomas, in press.

5 Heller, R H, and Palmer, L S, Pediatrics, 1978, 62, 52.

6 Campbell, S, Grundy, M, and Singer, J D, British Medical fournal, 1976, 2, 676.

7 Donnai, $\mathrm{P}$, et al, in preparation.

${ }^{8}$ Aberg, A, et al, Lancet, 1978, 2, 990.
}

\section{Erythropoietic protoporphyria}

In the metabolic disorders grouped together as the porphyrias one or more porphyrins are produced in excessive amounts; this is presumably due to a deficiency ${ }^{1}$ of one of the enzymes in the biosynthetic pathway that leads to haem, the ironcontaining portion of the haemoglobin molecule. Simple precursors, such as delta-aminolaevulinic acid and porphobilinogen, are converted into cyclic compounds (which may sensitise the skin to light) and the metabolic pathway continues through the tetrapyrroles formed from porphobilinogen and ends with protoporphyrin IX; this combines with iron to form haem. Porphyrins are probably made in all cells of the body, but the main sites are the liver and bone marrow.

There are two broad groups of porphyrias. In the hepatic porphyrias excess porphyrins are found mainly in the liver, while in the erythropoietic group the excess is mainly in the red cells. ${ }^{2}$ One of the most common of these rather unusual conditions is erythropoietic protoporphyria, which is characterised by the presence of excess protoporphyrin in the red cells, where it can be detected by fluorescence microscopy. In affected people attacks of acute photosensitivity occur shortly after exposure to sunlight, often starting with a burning sensation that may be almost intolerable and soon followed by erythema and swelling. Between attacks there is usually little evidence of the disease apart from mild superficial scars and thickening of exposed skin.

Some patients have liver abnormalities as well as skin manifestations, and in a few the liver damage may be severe and even fatal. They may also develop gall stones pigmented by porphyrin. ${ }^{3}$ The relatives of these patients may have mild abnormalities of liver function. Needle-shaped crystals and minor histological changes may also be found in liver biopsy samples from patients whose liver function has appeared normal, ${ }^{4}$ but the clinical significance of this finding is not yet clear.

The diagnosis of erythropoietic protoporphyria may be suspected clinically from the history and from the skin lesions.
Finding a raised concentration of red-cell protoporphyrin and fluorescent red cells confirms the clinical diagnosis. ${ }^{2}$ Erythropoietic protoporphyria must be differentiated from other eruptions caused by light, including xeroderma pigmentosum. Treatment is difficult. Beta-carotene by mouth is widely recommended, ${ }^{5}$ but its value has been questioned. ${ }^{6}$

Erythropoietic protoporphyria seems to be inherited as an autosomal dominant with partial penetrance; again the details are obscure. Latent forms exist, and these may be more common. The condition is widely distributed thoughout the world; in the south of England it is the porphyria most often seen by dermatologists.

A national register of cases of erythropoietic protoporphyria is being set up ( $\mathrm{p}$ 1508), and this should brighten the prospects for understanding the disease better. The register is intended to facilitate detailed follow-up of sufficient patients and some of their relatives, and so to clarify the natural history, prognostic factors, and genetic aspects. Effective trials of treatment should also now become possible.

4 Maxwell, J D, in Clinical Medicine and Therapeutics II, ed P Richards and H Mather, p 223. Oxford, Blackwell, 1979.

${ }^{2}$ Meyer, U A, and Schmid, R, in The Metabolic Basis of Inherited Diseases, 4th edn, ed J B Stanbury, J B Wyngaarden, and D S Fredrickson, p 1166. New York, McGraw-Hill, 1978.

${ }^{3}$ Cripps, D J, and Scheuer, P J, Archives of Pathology, 1965, 80, 500.

4 Thompson, R P H, et al, Gut, 1973, 14, 934.

${ }^{5}$ Mathews-Roth, M M, et al, fournal of the American Medical Association, 1974, 228, 1004.

${ }^{6}$ Corbett, M F, et al, British fournal of Dermatology, 1977, 97, 655.

\section{Antihypertensive treatment in the elderly}

Many physiological and pathological changes associated with advancing years modify both pharmacokinetics and the response to drugs in the elderly. Aging affects distribution, metabolism, and renal elimination of drugs and may cause changes in responsiveness. Doctors tend to prescribe more often for their elderly patients, who in turn are more likely to misunderstand or forget the prescriber's instructions; so the frequency of adverse drug reactions is hardly surprising-they are two to three times more common in patients over 60 than in younger adults. ${ }^{1}$ Since the incidence of hypertension increases with advancing years-and antihypertensive drug medication, once begun, is usually needed for the rest of the patient's lifetreatment for hypertension is one of the main causes of druginduced illness in the elderly. ${ }^{2}$ Clearly, therefore, treatment should be started only in the presence of well-defined and justifiable indications.

Hypertension is known to be an important risk factor for stroke and coronary heart disease in the elderly, ${ }^{3}$ but reducing the blood pressure has yet to be shown to diminish either morbidity or mortality. In 1973 the European Working Party on High Blood Pressure in the Elderly (EWPHE) was set up to study this problem. Since then more than 600 patients over 60 with mild-to-moderate hypertension have been allocated to two groups in a double-blind multicentre trial. Half the patients have been treated with a combination of hydrochlorothiazide and triamterene, methyldopa being added where control of blood pressure was not achieved; the other half have been given placebo. ${ }^{4}$

A review of the results so far has shown a significant 